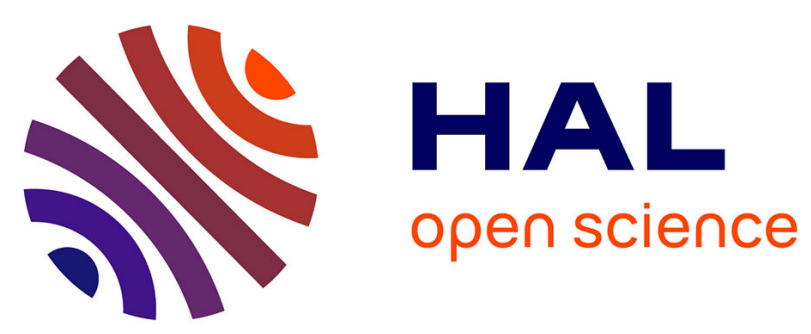

\title{
Strategies and considerations of G-protein-coupled receptor photopharmacology
}

\author{
Alice Berizzi, Cyril Goudet
}

\section{To cite this version:}

Alice Berizzi, Cyril Goudet. Strategies and considerations of G-protein-coupled receptor photopharmacology. Christopher J. Langmead. From Structure to Clinical Development: Allosteric Modulation of G Protein-Coupled Receptors, 88, Elsevier, pp.143-172, 2020, Advances in Pharmacology, 978-012-820187-9. 10.1016/bs.apha.2019.12.001 . hal-02863838

\section{HAL Id: hal-02863838 \\ https://hal.science/hal-02863838}

Submitted on 10 Jun 2020

HAL is a multi-disciplinary open access archive for the deposit and dissemination of scientific research documents, whether they are published or not. The documents may come from teaching and research institutions in France or abroad, or from public or private research centers.
L'archive ouverte pluridisciplinaire HAL, est destinée au dépôt et à la diffusion de documents scientifiques de niveau recherche, publiés ou non, émanant des établissements d'enseignement et de recherche français ou étrangers, des laboratoires publics ou privés. 
"From structure to clinical development: allosteric modulation of G Protein-Coupled Receptors"

Volume edited by Chris Langmead

Running title:

GPCR photopharmacology

Title:

Strategies and considerations of G Protein-Coupled Receptor photopharmacology

Authors:

Alice E. Berizzi and Cyril Goudet

Affiliation:

IGF, CNRS, INSERM, Univ. de Montpellier, Montpellier, F-34094 Montpellier, France

Corresponding authors contact information:

Alice E. Berizzi and Cyril Goudet, IGF, 141, rue de la Cardonille, F-34094 Montpellier Cedex

5, France. E-mail: alice.berizzi@igf.cnrs.fr and cyril.goudet@igf.cnrs.fr 


\section{Abstract (250 words)}

G protein-coupled receptor (GPCR) pharmacology tends to be complex and at times poorly understood. This has led to the development of GPCR-targeting agents that often demonstrate poor pharmacokinetic properties and poor selectivity for their target receptors. One approach that is emerging as a means of addressing these limitations is the use of molecules whose activity can be controlled by light. Photopharmacology involves the incorporation of a photoswitch into the structure of a given compound, cage or linker and following irradiation with light, undergoes a structural rearrangement, which changes its biological activity. The use of light-regulated ligands offers the opportunity to modulate and understand GPCR signalling in a more spatiotemporal manner than classical pharmacological approaches. In this chapter we will discuss some of the advancements that have been made in photopharmacology, particularly in developing photoswitchable ligands that target class A GPCRs, e.g. muscarinic acetylcholine receptors, class B GPCRs, e.g. glucagon-like peptide-1 receptor, and class C GPCRs, e.g. metabotrobic glutamate receptors. Given the intricacy of GPCR pharmacology, this chapter will also discuss some of the challenges the field faces when designing photopharmacological tools. Furthermore, it will propose that it is with a full appreciation of the spectrum of pharmacological and pharmacokinetic properties of photoswitchable ligands that research will be better placed to develop ligands with a reduced risk of failure during preclinical progression. This will likely enable photopharmacological approaches to continue to find novel applications and offer new perspectives in understanding (patho)physiology to ultimately inform future GPCR drug discovery efforts. 


\section{Keywords:}

GPCR, ligand, allosteric modulator, azobenzene, photochromic, photopharmacology, photo activated caged compound, photoswitchable tethered ligands

\section{Nonstandard abbreviations}

GPCR, guanine nucleotide-binding protein-coupled receptor; UV, ultraviolet; NAM, negative allosteric modulator; mGlu, metabotropic glutamate receptor; PTL, Photoswitchable tethered ligands; PORTL, photoswitchable orthogonal remotely tethered ligands; maPORTL, membrane anchored photoswitchable orthogonal remotely tethered ligands; PCL, photochromic ligands; mAChR, muscarinic acetylcholine receptor; ADME, absorption, distribution, metabolism, and excretion; ${ }^{1} \mathrm{H}-\mathrm{NMS}$, proton nuclear magnetic resonance; PIS, photoisomerization score; pPPS, negative logarithm of the photoinduced potency shift; $\mathrm{EC}_{80}$, $80 \%$ effective concentration; $\mathrm{plC}_{50}$, the concentration require to cause $50 \%$ inhibition; GLP1R, glucagon-like peptide-1 receptor; cAMP, cyclic adenosine monophosphate; PAM, positive allosteric modulator; NAL, neutral allosteric ligand; NMS, N-methylscopolamine; QNB, Quinuclidinyl benzilate; SAR, structure-activity relationship; GTPYS guanosine 5'-O-[ $\gamma$ thio]triphosphate; S1P, Sphingosine-1-phosphate. 


\section{Contents}

Introduction

$\begin{array}{ll}\text { Modality of photoactivable ligands } & 7\end{array}$

Modality of photoswitchable ligands 9

Tethered photoswitchable ligands 9

Freely-diffusible photoswitchable ligands $\quad 11$

Types of Photoswitchable cores $\quad 12$

Design Criteria for Photoswitchable drug-like compounds 13

Advantages and considerations for future applications of photopharmacology to

$\begin{array}{ll}\text { biological systems } & 18\end{array}$

$\begin{array}{lr}\text { Conclusion } & 26\end{array}$

$\begin{array}{lr}\text { Acknowledgements } & 27\end{array}$

$\begin{array}{ll}\text { Conflict of interest } & 27\end{array}$

$\begin{array}{lr}\text { Bibliography } & 28\end{array}$ 


\section{Introduction}

G-protein coupled receptors (GPCRs) represent the largest family of cell-surface receptors encoded by the human genome, and are necessary for the proper functioning of physiological responses (Lagerstrom and Schioth, 2008). Unsurprisingly, GPCRs have emerged as a major target class of drug discovery programs with drugs targeting GPCRs making-up a third of the total market share of therapeutics (Hauser et al, 2017; Overington et al, 2006). Despite their attractiveness as drug targets, one of the major challenges in GPCR drug discovery endeavours is the high attrition rate. Indeed, less than one third of GPCR-targeting agents entering phase III clinical trials receive FDA approval (Hauser et al, 2017). Poor selectivity, sub-optimal pharmacokinetic properties and a lack of efficacy remain the greatest obstacles for clinical candidates to overcome. For GPCRs, many of these issues are due to receptor pharmacology, (patho)physiology and candidate compound properties tending to be poorly understood prior to clinical advancement. Moreover, candidate molecules have historically been developed to exploit GPCR pharmacology via unidimensional approaches, which may be insufficient when attempting to treat complex diseases where multiple systems are affected.

To address these limitations there has been increased interest in the development of small molecules that use novel mechanisms to dynamically control their activity, and that are also well characterised in different pharmacological systems - considering (patho)physiological contexts and the effects of ligands on multiple signalling partners downstream from their target receptor. It is anticipated that research will be better equipped to recognise predictors of preclinical efficacy in the absence of adverse effects.

To this end, one approach gaining popularity is the development of molecules and technologies whose activity can be controlled by light. The use of light in this way, particularly in biological applications, can be advantageous as it is non-invasive, non-contaminating and photons are associated with low or negligible toxicity as compared to chemicals. Critically, light can be delivered in a highly controlled manner in space and time, and the extent of its effect can be controlled through the adjustment of wavelength and intensity. 
Historically, using light to control and manipulate biological processes has been important to the advancement of a number of fields of science, including neuroscience and pharmacology. For example, optogenetics is a method that utilises light to modulate the activity of specific cell types or organisms in a genetically targeted manner. Since its inception, it has helped address many fundamental research questions. However, this technique requires genetic manipulation of a system and so it may not be suitable for clinical advancement in all situations. Furthermore, since classical optogenetics often replaces a protein with a different, nonmammalian protein in order to allow for light modulation, its behaviour may differ from the endogenous protein, so direct conclusions about the endogenous system cannot be drawn with complete confidence. Irrespective of some of the limitations associated with optogenetics, other techniques have emerged that utilise light, which have become more commonplace in the clinic. Indeed, photodynamic therapy is approved for use in humans and is a minimally invasive therapeutic approach towards selectively killing malignant cells (Chilakamarthi \& Giribabu, 2017). This technique relies on the use of photosensitisers to form reactive oxygen species in living tissue, which leads to non-specific cell death. Due to its non-selective nature though, its application is limited.

More recently, the use of small, light-regulated ligands has emerged as an interesting alternative for the modulation of physiological systems and signalling pathways. Unlike optogenetics, the application of photopharmacology allows for the modulation of native proteins with minimal to no genetic manipulation, allowing easier translation into the clinic. Furthermore, many classical pharmacological approaches are unable to target proteins in a temporal and tissue-dependent manner. For this reason, photopharmacological strategies may be advantageous; since precise drug delivery and activity can be achieved.

In principal, photopharmacology involves the manipulation of a given biological process with a synthetic photoswitch; a moiety that undergoes a change in its structure upon irradiation with light, which can either irreversibly release an active compound or reversibly control a ligand's activity at its target. To date, photopharmacology approaches have been implemented in the 
design of candidate drug-like compounds for a number of biological targets, including Gprotein coupled receptors, ion channels, transporters, lipids, enzymes and elements of cytoskeleton (Cheng, Shchepakin, Kavanaugh, \& Trauner, 2017; Damijonaitis et al., 2015; Gomez-Santacana et al., 2017; Hull, Morstein, \& Trauner, 2018; Liu, Xie, Shao, \& Jiang, 2009; Pittolo et al., 2014; Rastogi et al., 2018; Tsai, Essig, James, Lang, \& Chin, 2015; Velema, Szymanski, \& Feringa, 2014). In this chapter, discussion will be restricted to light-regulated ligands that target GPCRs.

\section{Modality of photoactivable ligands}

At present, photopharmacology strategies targeting GPCRs can be designed to be either irreversible or reversible. Irreversible photopharmacological approaches including the development of photocaged compounds have grown in popularity, since they allow for greater control over the delivery and activity of a given drug at its site of action. For example, a photoactivable ligand can be administered systemically, but activated locally with the use of light and in this way can reduce the risk of adverse consequences in unwanted tissues. Photoactive caged-compounds possess a photoreactive component that is covalently bound to an active molecule, rendering it inactive to its target receptor. However, when exposed to irradiation of a select wavelength the active molecule is irreversibly released in a rapid and localised manner (Figure 1), thereby controlling the location and extent of its therapeutic effects and reducing the risk of adverse side-effects at other locations in the body.

[Insert Figure 1 here; total size one quarter of the page]

Since the first demonstration of the suitability of photocaged compounds to modulate biological systems in the late 1970s, a multitude of molecules employing this mechanism of action have emerged and shown promise in preclinical studies (Font et al., 2017; Kaplan, Forbush, \& Hoffman, 1978; Taura et al., 2018). For example, techniques incorporating photocaged compounds have found utility in describing the functional connectivity of circuits within the central nervous system. The use of photocaged-glutamate has indeed allowed for the mapping 
of circuits that connect with the hippocampus and cortex, while also bypassing some of the limitations associated with conventional stimulatory approaches, such as desensitization effects and artefacts of current (Callaway \& Katz, 1993). Many photoactive caged-compounds have also been designed to be sensitive to two-photon excitation and uncaging, which allows for high spatial resolution and minimal toxicity as compared to standard ultraviolet (UV) light excitation (Warther et al., 2010). Moreover, the photoactive caged compound, JF-NP-026 (caged-raseglurant; Figure 1B), which was based on the selective negative allosteric modulator (NAM) for the metabotropic glutamate receptor 5 (mGlu5), raseglurant, exhibits preclinical efficacy in mouse models of acute and neuropathic inflammatory pain (Font et al., 2017; Lopez-Cano, Font, Llebaria, Fernandez-Duenas, \& Ciruela, 2019). In this study, the authors demonstrated that caged-raseglurant had no effect on pain prior to illumination, but following photolysis with violet light either peripherally on the hind paw, or centrally in the thalamus, it demonstrated analgesic effects (Font et al., 2017). In this way, the authors of the study were able to examine targeted and localised effects of the ligand at the mGlu5 in a lightdirected manner that otherwise could not be achieved with conventional pharmacological approaches. They were also able to demonstrate the potential therapeutic efficacy of targeting this receptor with a selective photocaged NAM in different aspects of neuropathic pain. Another study has recently shown that the photo-caged $A_{2 A}$ antagonist, MRS7145, shows efficacy in a number of animal models that represent aspects of the symptomology of Parkinson's disease (Taura et al., 2018). Demonstrating the potential efficacy of photocaged $\mathrm{A}_{2 \mathrm{~A}}$ antagonists to manage the symptomology of movement disorders including, Parkinson's disease. More recently, a series of photocaged lipid metabolites enabling the optical control of GPCRs (FFAR1, PTGER1, LPA2, LPA3, PTFAR) have also been designed (Wagner, Schuhmacher, Lohmann, \& Nadler, 2019). For a more comprehensive list of GPCR-targeting photocaged compounds the reader is referred to another review (Ricart-Ortega, Font, \& Llebaria, 2019). 
Irrespective of these and other proof-of-concept studies, the use of photocaged compounds are limited by their irreversibility and care must be taken in their design to ensure efficient uncaging upon irradiation. For example, scenarios may arise where prior to irradiation the photocaged molecule is unreactive, but following illumination the biological activity of the parent ligand cannot be restored, or falls below the necessary threshold for biological activity due to incomplete uncaging (Deiters, 2010). The opposite may also occur, with a photocaged compound demonstrating activity prior to illumination leading to potential off-target or on-target effects in undesired tissues (Deiters, 2010).

\section{Modality of photoswitchable ligands}

In general, the design of reversible photoswitchable ligands involves the incorporation of an active moiety that can be selectively recognised by the target receptor and a photoswitchable core that reversibly isomerises under different light conditions. Following irradiation with distinct wavelengths of light the resulting photoisomers can interact differently with the target GPCR as a result of differences in pharmacological, chemical and/or physical properties. This results in the reversible control of a receptor from a state of activity to inactivity in a precisely timed manner. Often there is one photoisomer that is more thermodynamically stable. One wavelength of light will typically be used to switch the ligand to the less stable isomer, and it may return to the more thermodynamically stable isomer in darkness via thermal relaxation or by irradiation with a second wavelength.

\section{Tethered photoswitchable ligands}

Reversible photoswitchable ligands are classified depending on their interaction with their target protein. To date, photoswitchable molecules have been designed that can covalently attach to receptors via a bioconjugation, which can be synthetic or native to the receptor (Donthamsetti et al., 2017; Hermanson, 2013)(Broichhagen \& Trauner, 2014). Tethered photoswitchable ligand approaches include hybrid methods that exploit genetic and chemical technologies to control protein function, including the incorporation of unnatural amino acids 
into a receptor (Noren, Anthony-Cahill, Griffith, \& Schultz, 1989). The promise of this strategy is that it allows for greater selectivity for a target receptor and can rapidly oscillate between activating and inactivating a receptor, since its tether enables close proximity to its binding site (Figure 2) (Leippe, Koehler Leman, \& Trauner, 2017). This approach also allows any point on a receptor to be selectively targeted, but it does require genetic manipulation and the incorporation of unnatural amino acids can lead to decreased protein expression (Klippenstein, Ghisi, Wietstruk, \& Plested, 2014).

Tethered ligands are classified based on the proximity of the covalent attachment site to the ligand binding site. Photoswitchable tethered ligands (PTLs) possess a photoswitch and a covalent attachment, via a single cysteine amino acid in very close proximity to the ligand binding site, so when switching occurs the local concentration at the active site of the molecule is affected (Figure 2A). Alternatively, the bioconjugation to the receptor may occur with the use of larger protein tags, as is the case with photoswitchable orthogonal remotely tethered ligands (PORTLs; Figure 2B). For both PTLs and PORTLs, the active component binds to and elicits a pharmacological response at the receptor in one conformation, but does not bind in the second conformation following photoisomerization (Figure 2A and B). Both strategies have been successfully applied to metabotropic glutamate receptors (Carroll et al., 2015; Levitz et al., 2013)(Acosta-Ruiz, Broichhagen, \& Levitz, 2019; Broichhagen, Damijonaitis, et al., 2015). To date, the PORTL approach utilises a number of different noncovalent binders, including antibodies and nanobodies, as a means of attaching a photoswitchable ligand to a receptor with very high selectivity (Farrants et al., 2018).

Nanotweezers are another class of tethered photoswitchable ligand that employ lightresponsive cross-linkers, where each attachment point of the ligand to the receptor possesses a photoswitchable unit (Habermacher et al., 2016). Following isomerisation, the binding and functional activity of the ligand is affected at the receptor (Figure 2B). More recently, tethered ligands have been designed to genetically-target the plasma membrane of a cell instead of a target receptor and are named membrane anchored photoswitchable orthogonal remotely 
tethered ligands (maPORTL) (Donthamsetti et al., 2019). These ligands anchor to the plasma membrane and via lateral diffusion become close in proximity to their target receptor to enable interaction (Figure 2C).

[Insert Figure 2 here; total size half of a page]

The action of tethered photoswitchable ligands tend to be rapid since the local concentration and/or activity at the receptor can be switched from being very high to very low depending on the light condition. Unfortunately, the tethered ligand approach is also limited. They are often restricted to targeting points on a receptor that can only be accessed by the solvent; limiting interactions to the extracellular environment, photoswitching between each isomer is often inefficient, which can lead to reduced activity if photoisomerization is required for ligand binding, and the nature of the ligand's attachment to the receptor can increase the potential for non-specific reactions to occur, e.g. non-specific cysteine conjugations. To date though, no adverse effects have been reported and this approach has been successfully implemented to control some GPCRs in a light-dependent manner, including mGlu receptors and dopamine receptors (Broichhagen, Damijonaitis, et al., 2015; Donthamsetti et al., 2017). Research groups are beginning to address some of the limitations associated with this approach. For instance, a recent report describes the design of branched PORTLs as a means to improve the photoisomerization efficiency and affinity of tethered ligands (Acosta-Ruiz et al., 2019). Continued improvements of this type may lead to a set of tool compounds suitable for addressing a number of different mechanistic questions of receptor function in the future.

\section{Freely-diffusible photoswitchable ligands}

Of particular interest to this review, are photochromic ligands (PCLs). These are photoswitchable ligands that have been developed to interact with a receptor via non-covalent bonds. Like with covalently tethered compounds, photoswitchable molecules of this type can be designed so that following irradiation, photoisomers have opposing pharmacological 
interactions with the target receptor, which is a product of differences in isomer binding, activity and/or pharmacokinetic properties (Figure 3). In contrast, PCLs are freely diffusible and can be slower in switching between pharmacological responses. At present, PCLs have been synthesised to target all major GPCR classes and do so by many different mechanisms of action, including via orthosteric interactions (e.g. VUF15000 is a photoswitchable Histamine $\mathrm{H}_{3}$ receptor agonist and photoiperoxo is a photoswitchable muscarinic acetylcholine receptor [mAChR] partial agonist), allosteric interactions (e.g. alloswitch-1 is a photoswitchable mGlu5 NAM and PhotoETP is a photoswitchable positive allosteric modulator (PAM) of the glucagonlike peptide-1 receptor (GLP-1R), and by connections that engage aspects of both the orthosteric and allosteric sites of a receptor; that is by bitopic interactions (e.g. BQCAAI is a bitopic ligand for the $\mathrm{M}_{1} \mathrm{mAChR}$ ) (Agnetta, Kauk, Canizal, Messerer, Holzgrabe, et al., 2017; Broichhagen, Johnston, von Ohlen, \& Meyer-Berg, 2016; Broichhagen, Podewin, et al., 2015; Gomez-Santacana et al., 2017)(Jones et al., 2017)(Broichhagen et al., 2016; Hauwert et al., 2019; Schonberger \& Trauner, 2014). For a comprehensive list of currently available, GPCRtargeting PCLs the reader is referred to other reviews (Hull et al., 2018; Ricart-Ortega et al., 2019).

[Insert Figure 3 here; total size one quarter of the page]

\section{Types of Photoswitchable cores}

Photoreactive ligands incorporate photoswitchable cores, which are classified into two distinct groups - based on their mechanism of isomerisation. Following irradiation, molecules that incorporate azobenzene-, hemithioindigos- or stilbenes-based photoswitches into their structure will be interconverted between trans and cis isomers; leading to a substantial change in the overall shape and polarity of the molecule (Ricart-Ortega et al., 2019) (Figure 4A, B, C). Spiropyrans-, diarylethenes- or fulgides-based photoswitches can photoisomerize between open and closed formations, tending to result in changes in flexibility and electronic properties (Ricart-Ortega et al., 2019) (Figure 4D, E, F). To date, the azobenzene is the most widely used photoswitch; predominantly because it meets the majority of the design criteria for an ideal 
photoswitch (Agnetta, Kauk, Canizal, Messerer, \& Holzgrabe, 2017; Broichhagen, Frank, \& Trauner, 2015; Gomez-Santacana et al., 2017; Schonberger \& Trauner, 2014). Azobenzenes tend to be easy to synthesize, they are small in size, show high quantum yields and have little photobleaching (Beharry \& Woolley, 2011). The trans isomer tends to be the most stable and following irradiation to the cis form the molecule generally relaxes back to the trans isomer in darkness. The half-life of the thermodynamically less stable photoisomer can vary from milliseconds to days, depending on the substituents attached to the molecule. Many of the following examples will relate to azobenzene-based photoswitches.

[Insert Figure 4 here; total size one third of the page]

\section{Design Criteria for Photoswitchable drug-like compounds}

When designing a photoswitchable ligand there are a number of criteria determining the pharmacological success of the compound. First, photoswitchable ligands should be able to efficiently switch between their isomers following light irradiation. For most photoswitches it is not possible to completely convert all molecules from the thermodynamically preferred state to the less-stable state with irradiation. Research is progressing towards the development of bistable photoswitches though (Szymanski, Wu, Poloni, Janssen, \& Feringa, 2013), and this will be critical to the advancement of photoswitchable ligand development.

Importantly, a molecule may have different photoswitchable efficiencies depending on its local environment. Certainly the solvent system, concentration, temperature, $\mathrm{pH}$, presence of interacting molecules, whether the ligand is bound to its receptor and/or the disease context may affect its ability to photoisomerize (Velema et al., 2014). Taken together, studies should consider measuring isomer concentrations under all experimental conditions used, particularly when a photoswitchable ligand is intended for use in a disease context where physiological conditions are changed. This will ensure pharmacological profiles are attributed to the actions of a specific photoisomer of a ligand. 
An important factor for when determining the photoisomer ratio of a ligand is the half-life of the thermodynamically less stable photoisomer. Knowledge of the half-life of photoisomers will help to determine the appropriate dosing strategy for photoswitchable ligands and the amount of light required in order for a given pharmacological or therapeutic outcome. For instance, in an in vivo setting, for a candidate drug that is more active in the less stable isomeric form but that has a short isomeric half-life, it may be preferential to irradiate the molecule at its site of action and not prior to dosing. Using this method, the activity of the ligand will not be lost by the time it reaches its target and it will be less likely to elicit undesirable on-target effects in other tissues. As with the photoisomer ratio of a molecule, it is feasible that the thermal relaxation time may change depending on the local environment of the photoswitchable ligand and as such, care must be taken to fully appreciate the properties of the ligand in changing environmental conditions.

As well as the photoisomer ratio, the metabolism of the photoswitchable ligand and the activity of the resulting metabolites should also be considered. Previous reports show that photoswitchable moieties such as azobenzenes can be subject to either enzymatic degradation or glutathione-mediated reduction depending on their polarity (Boulegue, Loweneck, Renner, \& Moroder, 2007; Renner \& Moroder, 2006; Zbaida, 1995). Accordingly, the electronic properties of molecules should be examined in the design process of photoswitchable ligands and the synthesised ligands should be tested against glutathionemediated reduction (Velema et al., 2014). Photoswitchable ligands containing azobenzene cores, nevertheless, have shown in vivo efficacy suggesting that their potential for metabolism may not be a limiting factor (Font et al., 2017; Taura et al., 2018; Zussy et al., 2018)(Mehta et al., 2017; Morstein et al., 2019).

The chosen photoswitch should also demonstrate negligible toxicity. Some azobenzenes and their metabolites have reported toxicity (Brown \& De Vito, 1993). However, this may not be a restricting factor since drugs containing azobenzenes have been successfully progressed to the clinic for therapeutic use (McGirt, Vasagar, Gober, Saini, \& Beck, 2006). 
Taken together, as with classical pharmacological approaches, it is clear that adequate knowledge of the overall ADME (absorption, distribution, metabolism, and excretion) properties of a photoswitchable ligand is essential in the design process and is critical to reducing risks associated with their failure towards further optimisation and advancement. One of the main advantages that photoswitchable strategies possess over classical pharmacological approaches is that given adequate knowledge of pharmacodynamic and ADME properties, it is possible to fine-tune some aspects of an existing photoswitchable ligand in real-time, and in a spatial and temporal manner with light. For this reason, ensuring that a photoswitchable ligand is designed such that the photoisomerization occurs at very precise wavelengths is paramount. When evaluating the appropriateness of a wavelength for photoswitching, its corresponding photostationary state (a function of the wavelength of light) is important. In theory, the photostationary state is reached when the interconversion between cis and trans isomers of a molecule proceeds at equilibrium and the isomeric ratio remains constant. Ideally, the absorption spectra of each isomer will be well separated and the isomeric ratio at the photostationary state will be approximately equal to 99:1. This is not always the case though, and the isomeric ratio can be much lower, and as a consequence of the nonlinear nature of biological systems a small change in this ratio may have a substantial effect on the biological activity of the photoswitchable ligand.

In general, the isomeric ratio of a photoswitchable ligand's photostationary state, at a given wavelength, can be determined with the use of a ${ }^{1} \mathrm{H}-\mathrm{NMR}$ spectroscopy assay (Banghart \& Trauner, 2013). This assay involves dissolving samples of a photoswitchable ligand into deuterated water and analysing them firstly by UV-visible spectroscopy to identify which wavelengths produce a photostationary state and then the ratios can be determined by ${ }^{1} \mathrm{H}-$ NMR spectroscopy. Since the aromatic protons of azobenzene trans and cis isomers exhibit different chemical shifts it makes it possible to compare the relative abundance of each isomer for a particular photostationary state of a ligand by peak integration. Regular employment of a 
technique such as ${ }^{1} \mathrm{H}$-NMR spectroscopy is recommended as it allows for the direct measurement of a photoswitchable ligand's photostationary states.

The wavelengths for photoswitching should also occur outside the UV range to reduce toxicity so that they are appropriate for clinical use. Recently, red-shifted, azobenzenes-based photoswitches have been synthesised, which penetrate tissue more deeply and are more biocompatible (Broichhagen et al., 2015; Dong, Babalhavaeji, Samanta, Beharry, \& Woolley, 2015; Samanta et al., 2013). It should be noted though, that the substitution pattern of a ligand's photoswitchable core cannot only significantly influence the wavelengths required for interconversion between isomers but also can affect photoisomerization rates and photorelaxation times, which should be considered when designing ligands (Dong, Babalhavaeji, Samanta, Beharry, \& Woolley, 2015). Taken together, the design of the ideal photoswitch should enable bi-directional photoisomerization with wavelengths that are wellseparated in the light spectrum, that are deep-penetrating and show low toxicity to reduce invasiveness.

To determine the most appropriate wavelengths for photoswitching of a ligand, a researcher can determine the photoisomerization score (PIS) and the negative logarithm of the photoinduced potency shift (pPPS) for a small molecule (Gomez-Santacana et al., 2017). The PIS is calculated from the data obtained from the UV-visible absorption spectra of ligands and is given as a score ranging from zero to one; where a score of zero is indicative of a wavelength that results in no isomerisation and a score of one refers to complete isomerisation following irradiation. Two PIS values are usually determined - one for the interconversion from the trans to cis isomer $\left(\mathrm{PIS}_{\mathrm{T} \rightarrow \mathrm{C}}\right)$ and the other for the conversion of the cis to trans isomer $\left(\mathrm{PIS}_{\mathrm{C} \rightarrow \mathrm{T}}\right)$. The value for the trans to cis conversion represents the difference between the absorbance under dark light conditions and illuminated conditions (usually violet light for an azobenzene) over the absorbance for dark light conditions of a ligand (Equation 1). The resulting value can then be compared against a reference photoswitchable ligand that undergoes complete isomerisation (Equation 1). For determining the $\mathrm{PIS} \mathrm{C}_{\mathrm{C} \rightarrow \mathrm{T}}$ value the same 
equation is used, but the maximum absorbance occurring under violet light conditions is compared to a second wavelength, which promotes isomerisation back to the trans form (usually green light for azobenzenes) (Equation 2).

$$
P I S_{x, t \rightarrow c}=\frac{\frac{A_{x, \text { dark maximum }}-A_{x, \text { violet }}}{A_{x, \text { dark maximum }}}}{\frac{A_{\text {ref }, \text { dark maximum }}-A_{\text {ref }, \text { violet }}}{A_{\text {ref }, \text { dark maximum }}}}
$$

(Equation 1)

$$
P I S_{x, c \rightarrow t}=\frac{\frac{A_{x, \text { violet }}-A_{x, \text { green }}}{A_{x, \text { dark maximum }}}}{\frac{A_{\text {ref,dark maximum }}-A_{\text {ref }, \text { violet }}}{A_{\text {ref }, \text { dark maximum }}}}
$$

(Equation 2)

The pPPS value for a photoswitchable ligand measures the change in potency of a molecule following irradiation with a wavelength of light as compared to its potency under dark light conditions (Gomez-Santacana et al., 2017) (Figure 5). For example, in the case of an $\mathrm{EC}_{80}$ concentration of an agonist interacted with a concentration response curve of a photoswitchable NAM under dark light and illuminated conditions, the pPPS value is determined from the difference between the illuminated curve $\mathrm{pIC}_{50}$ value and the dark light curve $\mathrm{pIC}_{50}$ value (Figure 5). The resulting value will aid a researcher in choosing a wavelength of light for future experiments that has the largest activity difference for a photoswitchable ligand between isomerisation states. Once the appropriate wavelength has been chosen, it is also possible to determine pPPS values for different light intensities to maximise photoswitching at a particular wavelength.

[Insert Figure 5 here; total size one fifth of the page] 


\section{Advantages and considerations for future applications of photopharmacology to biological systems}

As outlined previously, the benefit of using photoswitchable ligands is the ability to control their action externally, in real-time and in a reversible manner. These specific properties may allow photopharmacology approaches to be easily incorporated and applied to a number of research areas towards improving GPCR drug discovery, including in developing our understanding of GPCR signalling and function.

The consideration of the pharmacokinetic and pharmacodynamic properties of drug-like compounds is essential to the success of any GPCR drug discovery program. Since these properties are dictated by the shape, structure and polarity of a drug, being able to rapidly change these aspects of a molecule may allow for dynamic control over the activity, effectiveness and amount of drug that reaches its site of action. Photopharmacology, therefore, offers the potential benefit of designing drug-like molecules with pharmacokinetic and pharmacodynamics properties that can change under different conditions. For instance, a photoswitchable ligand may be designed to be more lipophilic at a particular $\mathrm{pH}$ to allow for better absorption at one point of the gastrointestinal system, which may improve the overall effectiveness of the compound. Alternatively, it may be possible to design a photoswitchable ligand to photoisomerize from a low affinity/efficacy state in tissues where its activity is not desired, to a high affinity/efficacy state upon reaching its site of action to minimise off-target effects in undesired tissues. Certainly, strategies of this type would be beneficial when treating many types of cancers that are sub-optimally treated with cytotoxic drugs. This potential benefit has recently been demonstrated with the photocaged mGlu5 NAM; caged-raseglurant, which shows a reduced side-effect profile as compared to its parent compound, raseglurant (Font et al., 2017).

Currently, many of the photoswitchable ligands available that target GPCRs are more active in their more thermodynamically stable form (trans isomer), which means they are active under 
dark light conditions and have to be deactivated with light. For therapeutic purposes, inactive ligands that can be switched on by light are more desirable and to date few GPCR targeting cis-active ligands have been described, including the photoswitchable cis-on cannabinoid receptor 1 agonist, azo-THC-4, (Westphal et al., 2017), and the cis-on antagonist of the histamine $\mathrm{H}_{3}$ receptor, VUF14862 (Hauwert et al., 2018). Studies have also emerged that describe alternative photoswitchable ligands that are more thermodynamically stable in their cis form, while their trans isomer tends to be severely strained and distorted in shape. Ligands of this type generally possess two phenyl rings connected by an ethylene bridge, which creates a locked-azobenzene core. Using this strategy, compounds have been designed that are inactive under dark light conditions and more active following light irradiation (Cabre et al., 2019; Thapaliya, Zhao, \& Ellis-Davies; Trads et al., 2019; (Siewertsen et al., 2009; Siewertsen, Schonborn, Hartke, Renth, \& Temps, 2011). To date, molecules of this type have only been designed to target non-GPCR proteins so it remains to be seen if GPCR-targeting photoswitchable ligands can be designed in this way.

In the field of GPCR pharmacology and drug discovery, the discovery of biased signalling has been an important development. Biased signalling describes the ability of ligands to act at the same GPCR and preferentially stabilise different conformational states to elicit distinct cellular and pharmacological outcomes (Christopoulos, 2014; Terry Kenakin, 2005; Wootten, Christopoulos, Marti-Solano, \& Babu, 2018). In the context of GPCR drug discovery, this concept has opened the door for the design of drug-like compounds which are biased towards particular signalling outcomes at the exclusion of others. This will mean that ligands can be tailored to have improved activity and/or reduced risk for adverse effects. In this way, the application of photopharmacology may provide an interesting approach to improve our understanding of biased agonism and modulation at GPCRs in an in vitro and in vivo setting, and as a tool to implement desired biases in a reversible manner into candidate ligands for preclinical development. For instance, photoswitchable agonists or allosteric modulators may be developed to photoisomerize between forms that stabilise different conformational states 
of a receptor so that properties, including the kinetics of the ligand-receptor interaction (e.g. ligand-residency time), the signalling efficacy and/or the receptor trafficking can be altered. Following a thorough investigation into the spectrum of photoswitchable ligand effects under different light conditions, it may then be possible to build on structure-activity relationships around GPCRs in conjunction with structural and modelling data.

Evidence for biased signalling of photoswitchable ligands at GPCRs is already emerging. Based on the glucagon-like peptide-1 receptor (GLP-1R) agonist liraglutide, Broichhagen et al., (2015) designed a photoswitchable incretin memetic termed LirAzo (Broichhagen, Podewin, et al., 2015). In the trans configuration, LirAzo was suggested to preferentially facilitate calcium influx in pancreatic $\beta$-cells, while the cis isomer was suggested to preferentially promote cAMP production. The potential for light-sensitive bias of this compound for GLP-1R signalling translated to differential effects on glucose stimulated insulin secretion in pancreatic $\beta$-cells and in the ligand's ability to protect $\beta$-cells from glucolipotoxic insult (Broichhagen, Podewin, et al., 2015). In a follow-up study, the same group extended on this approach towards rationally designing GLP-1R photoswitchable PAMs, which demonstrated distinct binding kinetic and signalling profiles (Jones et al., 2017). This study provided the first evidence for GLP-1R PAMs to markedly augment agonist-residency times at their receptor, which may contribute to the underlying mechanism driving their potential for signalling bias and modulatory profiles, and it offers a novel therapeutic strategy for achieving sustained responses in vivo (Jones et al., 2017). Taken together, these studies demonstrate the potential for designing biased photoswitchable orthosteric and/or allosteric ligands to reveal the mechanisms underlying GPCR signalling bias and its (patho)physiological consequences.

Although exciting, these studies highlight the complexity of GPCR signalling and the necessity of testing putative photoswitchable ligands of GPCRs against multiple functional based assays, so that orthosteric- and allosteric-targeting ligand efficacy and/or allosteric modulation-induced biases of endogenous ligands can be assessed (Christopoulos, 2014). Furthermore, future studies that intend on assessing and quantifying bias profiles for 
photoswitchable ligands should ensure that they compare the profile of each ligand against a reference ligand and a reference pathway, since quantitative methods for measuring ligand efficacy can differ greatly depending on the context of the interaction, for example cell background. For further advice on quantifying and understanding bias the reader is referred to other papers (Rajagopal et al., 2011; Wootten, Christopoulos, Marti-Solano, Babu, \& Sexton, 2018).

Adding further complexity to receptor pharmacology, allosteric interactions at GPCRs can also demonstrate another unique characteristic, which is related to biased agonism and modulation, termed probe dependence (Christopoulos, 2014; Terry Kenakin, 2005). This phenomenon refers to how the magnitude and direction of an allosteric effect at a particular GPCR can change depending on the nature of the interacting orthosteric ligand. For instance, the muscarinic acetylcholine receptor (mAChR) allosteric ligand, LY2033298, has been shown to act as a PAM of acetylcholine function at the $\mathrm{M}_{4} \mathrm{mAChR}$, but as a neutral allosteric ligand (NAL) when interacted with the inverse agonists, $\left[{ }^{3} \mathrm{H}\right] \mathrm{N}$-methylscopolamine $\left(\left[{ }^{3} \mathrm{H}\right] \mathrm{NMS}\right)$ or $\left[{ }^{3} \mathrm{H}\right]$ quinuclidinyl benzilate $\left(\left[{ }^{3} \mathrm{H}\right] \mathrm{QNB}\right)$ at the same receptor (Leach et al., 2010). This potential for probe-dependent effects may be of particular importance when attempting to appreciate the pharmacology of photoswitchable allosteric ligands. Since ligands of this type are usually designed to have different levels of activity in each photoisomeric form, it is conceivable that each photoisomer may demonstrate different types and levels of cooperativity with a variety of co-binding orthosteric probes at the same receptor. In this way, a PCL may photoswitch between PAM to NAL activity when co-bound with an endogenous ligand at a receptor, but NAM to PAM activity when interacted with a different orthosteric probe. The potential for probedependent effects of different photoisomers will make it possible to investigate multiple pharmacological effects within the same assay. This property also necessitates studies to thoroughly investigate the pharmacological profile of an allosteric PCL if it is intended to be interacted with multiple endogenous or synthetic orthosteric probes in vivo, prior to preclinical advancement. 
When considering stimulus bias and probe dependent effects, it is unsurprising that structureactivity relationships (SAR) of allosteric ligands for GPCRs tend to be shallow; with subtle changes in molecular structures resulting in substantial changes in activity (molecular switches) (Conn, Lindsley, Meiler, \& Niswender, 2014; Gregory \& Conn, 2015; Lindsley, 2014). For this reason, the development and design of photoswitchable allosteric ligands may be particularly challenging, as the addition of a photoswitchable unit to an existing allosteric ligand may render it inactive or alter its pharmacological profile. Molecular switches of this type have been relatively well-documented, with very slight changes in structure leading to cooperativity switches at the receptor with the same interacting orthosteric probe (Wood, Hopkins, Brogan, Conn, \& Lindsley, 2011). Indeed, this has allowed for the design of mGlu PAMs, NAMs and NALs to be generated all from the same parent scaffold (Wood et al., 2011). Similarly, the tendency for molecular switching could also be used for the development of improved photoswitchable modulators. For instance, alloswitch-1 was the first photoswitchable allosteric ligand to be described, which acts as a NAM at the mGlu5 (Pittolo et al., 2014). Intriguingly, alloswitch-1 was based on the scaffold of a potent mGlu4 PAM, but with the strategic addition of an azobenzene core its activity switched to negative cooperativity with glutamate at the mGlu5, and this NAM activity is reversibly controlled by irradiation with different wavelengths of light (Pittolo et al., 2014) (Figure 3B). Furthermore, in a recent communication by GomezSantacana et al., (2018), photoswitchable orthosteric-targeting ligands for the chemokine receptor CXCR3 were rationally designed to have efficacy photoswitches in a ${ }^{35}$ S]GTPYS binding assay. They showed that depending on the light condition, orthosteric-targeting small molecules could bind to the CXCR3 and demonstrate either full, partial or no agonism at the receptor (Gomez-Santacana, de Munnik, Vijayachandran, Da Costa Pereira, \& Bebelman, 2018). This study illustrates that not only allosteric PCLs, but also orthosteric PCLs can be designed to have subtle structural differences, which result in significant changes in pharmacological activity. 
Further intricacy is added to GPCR photopharmacology with the prospect of photoswitchable ligands exhibiting species differences and/or activity differences at splice variants of GPCRs. These effects can occur as a result of changes in affinity for allosteric sites due to differences in receptor homology between species or as a product of changes in cooperativity (Leach et al., 2013; Suratman et al., 2011). Properties like these necessitate PCLs to be screened against receptors of different species and any splice variants that may exist for a receptor under different light conditions. This ensures that the appropriate preclinical model is chosen to test for in vivo efficacy, and informs research of any side effects that may occur as a result of changed functional activity of a PCL at different polymorphisms of a receptor. It is anticipated that this would reduce the risk of drug failure during clinical progression.

Another interesting consideration for photoswitchable allosteric ligands is the concept of lateral allostery. Lateral allostery describes the effects of a ligand that are expressed along the plane of a cell membrane to other GPCRs or membrane proteins, and can lead to receptor dimerization or heterodimerization (Kenakin \& Miller, 2010). In this way it is possible that a photoswitchable ligand can demonstrate differences in lateral allosteric effects in different isomeric forms, which could lead to changes in the way proteins interact with each other at the surface of a cell. This becomes particularly important when a target receptor dimerizes with different partners in different cell or tissue types. For example, mGlu2 and mGlu4 receptors are thought to form heterodimers and the interaction of allosteric- and orthosterictargeting ligands at this heterodimer as compared to the mGlu4 homodimer have shown activity differences (Gonzalez-Maeso et al., 2008; Kammermeier, 2012; Yin et al., 2014). In this regard, it may be possible to design PCLs that have distinct selectivity profiles for dimers in each isomeric form. Certainly, the functional selectivity of some antipsychotics have already been linked with the existence of dimers (Brea et al., 2009; Maroteaux, Bechade, \& Roumier, 2019).

Given the challenges that changes in cooperativity present in photoswitchable allosteric drug discovery programs and in the interpretation of SAR, there is a clear need for a multi- 
disciplinary approach towards identifying active and inactive photoswitchable allosteric ligands. To date, many drug discovery programs rely on the results of modulator potency curves in one signalling pathway and in the presence of a single agonist concentration, which may not be the endogenous ligand or may be one of multiple endogenous ligands for a receptor. As described earlier though, photoswitchable allosteric ligands may demonstrate signalling bias and/or probe dependence, which may lead to active ligands being overlooked in high throughput screens if they are not tested for under appropriate conditions. In the case of GPCRs with multiple endogenous ligands, if an allosteric PCL is selected for its envisioned PAM activity at a receptor but is only tested against one of the endogenous ligands, it may be found to have unexpected effects at the receptor due to uncharacterised cooperativity with a second ligand. Indeed, this is the case for the chemokine receptor type 5 allosteric modulator, aplaviroc, which demonstrates probe dependent effects with the endogenous ligands of the receptor (Watson, Jenkinson, Kazmierski, \& Kenakin, 2005). The use of potency curves in drug screens provides an overall measure of affinity, efficacy and cooperativity of a ligand, so any modifications made to a chemotype in order to understand the influence of a single parameter over the activity of the ligand will not be possible from a single potency readout of a compound. It is clear that more quantitative and qualitative analysis of photoswitchable allosteric ligand effects is necessary to understand how structures of photoswitchable ligands relate to their effects at a receptor under different light conditions.

Taken together, photopharmacological approaches offer the opportunity to better control, modulate and understand GPCR pharmacology in a more spatial and temporal manner than classical pharmacological approaches. However, given the complexity of GPCR pharmacology the development of photopharmacological tools, such as allosteric PCLs, are still subject to many of the same challenges that current approaches face when attempting to target GPCRs.

Despite these challenges, the use of photopharmacology is still in its infancy and many of its applications are yet to be realised. In studies investigating the biophysical properties of 
receptors the use of photocaged compounds and tethered ligand approaches could allow for the probing of receptor onset kinetics, with PTL and PORTL approaches allowing for the dynamic control of receptor activity without being impeded by issues including ligand diffusion (Leippe, Koehler Leman, \& Trauner, 2017). In this way, photopharmacological approaches can mimic the time course of neurotransmitter release from the synaptic cleft and be amenable to studies where access to receptor populations is not as accessible for traditional pharmacological or electrophysical approaches, for example at pre- or post-synaptic sites or subcellular compartments (Reiner \& Levitz, 2018). This may help research to study receptors in a compartment-specific manner to provide information about the receptor trafficking and compartmentalization mechanisms of a receptor. It would also be possible to investigate the signalling of a target receptor in a graded manner by changing the light intensity and/or wavelength used to photoisomerize a PCL; potentially enabling researchers to test multiple pharmacological conditions in one experiment (Figure 6).

[Insert Figure 6 here; total size one quarter of the page]

Advantages of photopharmacogical approaches to mimic the extent, direction and magnitude of endogenous effects in real-time, may also make them better suited to understanding physiological and behavioural changes in vivo. To date, applying allosteric PCLs to the environment of frog tadpoles or fish larvae modulates the swimming behaviours of these animals in a light-dependent manner (Gomez-Santacana et al., 2017; Pittolo et al., 2014; Rovira et al., 2016). The practicality of controlling neuromodulatory mechanisms in freelymoving rodents has also been demonstrated. As previously mentioned, photo-controllable ligands that target mGlu receptors demonstrate analgesic activity both peripherally and centrally in mice, while photoswitchable analogues of Sphingosine-1-phosphate (S1P) can reversibly control S1P3-dependent hypersensitivity to pain of rodents (Font et al., 2017; Morstein et al., 2019; Zussy et al., 2018). The photocaged $A_{2 A}$ adenosine receptor antagonist, MRS7145, was also recently shown to demonstrate efficacy in reversing motor impairment in a preclinical model of Parkinson's disease (Taura et al., 2018). 
These studies have demonstrated the potential benefit and feasibility of applying photopharmacological approaches in an in vivo setting and may pave the way for opportunities for innovation in light-regulated therapeutics. One major obstacle that may prevent photopharmacological methods from being translated into the clinic though, will be the ability to deliver light in a precise way to specific regions of the body. At present, preclinical studies have led to the design of devices that can deliver light with minimal damage to neural tissue while also being wireless, small in size, injectable and remotely controlled (Kim et al., 2013; Qazi et al., 2019; Shin et al., 2017). Some designs have also made it possible to control both drug delivery and the activity of light at a particular site of action through the use of optofluidic systems (Jeong et al., 2015). Moreover, the design of photoswitchable ligands that photoisomerize with the application of deep-tissue penetrating wavelengths, such as red or infrared light have now been synthesised, which may remove the need for more invasive approaches that require light emitting implants (Dong et al., 2015). Furthermore, in diseases that affect the skin, eyes and other tissues that are easily accessible by light photopharmacological approaches may find their greatest clinical utility without the need of more invasive approaches (Tochitsky, Trautman, Gallerani, Malis, \& Kramer, 2017). Given these advancements, it is likely that photopharmacological approaches will continue to find novel applications and offer new perspectives in understanding (patho)physiology to ultimately inform future GPCR drug discovery efforts.

\section{Conclusion}

The current state of the field of photopharmacology is rapidly advancing. The development of novel modalities of photoswitchable ligands and ways to implement them into and modulate biological systems is constantly adapting and improving. It is true that the application of photopharmacology in GPCR research offers the opportunity to better understand receptor pharmacology in a more spatial and temporal manner. However, the complexity of GPCR pharmacology means the development of photopharmacological tools, including allosteric PCLs, is likely to encounter many challenges that traditional pharmacological approaches 
experience when targeting GPCRs. Once well-understood, some characteristics currently posing challenges for research - such as changes in cooperativity - could be used to fine-tune the activity of photoswitchable allosteric ligands.

\section{Acknowledgements}

The authors thank Jack Delaney for critical reading of the manuscript. AEB was supported by the Labex EpiGenMed (program « Investissements d'avenir », ANR-10-LABX-12-01). CG was supported by grants from the Agence Nationale de la Recherche (ANR-16-CE16-0010-01 and ANR-17-NEU3-0001-01 under the frame of Neuron Cofund).

\section{Conflict of interest}

Authors declare no conflict of interest. 


\section{Bibliography}

Acosta-Ruiz, A., Broichhagen, J., \& Levitz, J. (2019). Optical Regulation of Class C GPCRs by Photoswitchable Orthogonal Remotely Tethered Ligands. Methods Mol Biol, 1947, 103-136. doi: 10.1007/978-1-49399121-1_6

Acosta-Ruiz, A., Gutzeit, V. A., Skelly, M. J., Meadows, S., Lee, J., Orr, A. G., . . Levitz, J. (2019). Branched photoswitchable tethered ligands enable ultra-efficient optical control and detection of class $\mathrm{C} G$ proteincoupled receptors. bioRxiv, 563957. doi: 10.1101/563957

Agnetta, L., Kauk, M., Canizal, M. C. A., Messerer, R., Holzgrabe, U., Hoffmann, C., \& Decker, M. (2017). A Photoswitchable Dualsteric Ligand Controlling Receptor Efficacy. Angew Chem Int Ed Engl, 56(25), 72827287. doi: 10.1002/anie.201701524

Agostinis, P., Berg, K., Cengel, K. A., Foster, T. H., Girotti, A. W., Gollnick, S. O., . . . Golab, J. (2011). Photodynamic therapy of cancer: an update. CA Cancer J Clin, 61(4), 250-281. doi: 10.3322/caac.20114

Banghart, M. R., \& Trauner, D. (2013). A $1 \mathrm{H}$ NMR assay for measuring the photostationary States of photoswitchable ligands. Methods Mol Biol, 995, 107-120. doi: 10.1007/978-1-62703-345-9_8

Beharry, A. A., \& Woolley, G. A. (2011). Azobenzene photoswitches for biomolecules. Chem Soc Rev, 40(8), 44224437. doi: $10.1039 / \mathrm{c} 1 \mathrm{cs} 15023 \mathrm{e}$

Boulegue, C., Loweneck, M., Renner, C., \& Moroder, L. (2007). Redox potential of azobenzene as an amino acid residue in peptides. Chembiochem, 8(6), 591-594. doi: 10.1002/cbic.200600495

Brea, J., Castro, M., Giraldo, J., Lopez-Gimenez, J. F., Padin, J. F., Quintian, F., . . Loza, M. I. (2009). Evidence for distinct antagonist-revealed functional states of 5-hydroxytryptamine(2A) receptor homodimers. Mol Pharmacol, 75(6), 1380-1391. doi: 10.1124/mol.108.054395

Broichhagen, J., Damijonaitis, A., Levitz, J., Sokol, K. R., Leippe, P., Konrad, D., . . Trauner, D. (2015). Orthogonal Optical Control of a G Protein-Coupled Receptor with a SNAP-Tethered Photochromic Ligand. ACS Cent Sci, 1(7), 383-393. doi: 10.1021/acscentsci.5b00260

Broichhagen, J., Frank, J. A., Johnston, N. R., Mitchell, R. K., Smid, K., Marchetti, P., . . Hodson, D. J. (2015). A red-shifted photochromic sulfonylurea for the remote control of pancreatic beta cell function. Chem Commun (Camb), 51(27), 6018-6021. doi: 10.1039/c5cc01224d

Broichhagen, J., Frank, J. A., \& Trauner, D. (2015). A roadmap to success in photopharmacology. Acc Chem Res, 48(7), 1947-1960. doi: 10.1021/acs.accounts.5b00129

Broichhagen, J., Johnston, N. R., von Ohlen, Y., Meyer-Berg, H., Jones, B. J., Bloom, S. R., . . Hodson, D. J. (2016). Allosteric Optical Control of a Class B G-Protein-Coupled Receptor. Angew Chem Int Ed Engl, 55(19), 5865-5868. doi: 10.1002/anie.201600957

Broichhagen, J., Podewin, T., Meyer-Berg, H., von Ohlen, Y., Johnston, N. R., Jones, B. J., . . Trauner, D. (2015). Optical Control of Insulin Secretion Using an Incretin Switch. Angew Chem Int Ed Engl, 54(51), 1556515569. doi: 10.1002/anie.201506384

Broichhagen, J., \& Trauner, D. (2014). The in vivo chemistry of photoswitched tethered ligands. Curr Opin Chem Biol, 21, 121-127. doi: 10.1016/j.cbpa.2014.07.008

Brown, M. A., \& De Vito, S. C. (1993). Predicting azo dye toxicity. Critical Reviews in Environmental Science and Technology, 23(3), 249-324. doi: 10.1080/10643389309388453

Cabre, G., Garrido-Charles, A., Gonzalez-Lafont, A., Moormann, W., Langbehn, D., Egea, D., . . Hernando, J. (2019). Synthetic Photoswitchable Neurotransmitters Based on Bridged Azobenzenes. Org Lett, 21(10), 3780-3784. doi: 10.1021/acs.orglett.9b01222

Callaway, E. M., \& Katz, L. C. (1993). Photostimulation using caged glutamate reveals functional circuitry in living brain slices. Proc Natl Acad Sci U S A, 90(16), 7661-7665. doi: 10.1073/pnas.90.16.7661

Carroll, E. C., Berlin, S., Levitz, J., Kienzler, M. A., Yuan, Z., Madsen, D., . . . Isacoff, E. Y. (2015). Two-photon brightness of azobenzene photoswitches designed for glutamate receptor optogenetics. Proc Natl Acad Sci U S A, 112(7), E776-785. doi: 10.1073/pnas.1416942112

Cheng, B., Shchepakin, D., Kavanaugh, M. P., \& Trauner, D. (2017). Photoswitchable Inhibitor of a Glutamate Transporter. ACS Chem Neurosci, 8(8), 1668-1672. doi: 10.1021/acschemneuro.7b00072

Chilakamarthi, U., \& Giribabu, L. (2017). Photodynamic Therapy: Past, Present and Future. Chem Rec, 17(8), 775802. doi: $10.1002 /$ tcr.201600121

Christopoulos, A. (2014). Advances in G protein-coupled receptor allostery: from function to structure. Mol Pharmacol, 86(5), 463-478. doi: 10.1124/mol.114.094342 
Conn, P. J., Lindsley, C. W., Meiler, J., \& Niswender, C. M. (2014). Opportunities and challenges in the discovery of allosteric modulators of GPCRs for treating CNS disorders. Nat Rev Drug Discov, 13(9), 692-708. doi: 10.1038/nrd4308

Damijonaitis, A., Broichhagen, J., Urushima, T., Hull, K., Nagpal, J., Laprell, L., . . Trauner, D. (2015). AzoCholine Enables Optical Control of Alpha 7 Nicotinic Acetylcholine Receptors in Neural Networks. ACS Chem Neurosci, 6(5), 701-707. doi: 10.1021/acschemneuro.5b00030

Deiters, A. (2010). Principles and applications of the photochemical control of cellular processes. Chembiochem, 11(1), 47-53. doi: 10.1002/cbic.200900529

Dong, M., Babalhavaeji, A., Samanta, S., Beharry, A. A., \& Woolley, G. A. (2015). Red-Shifting Azobenzene Photoswitches for in Vivo Use. Acc Chem Res, 48(10), 2662-2670. doi: 10.1021/acs.accounts.5b00270

Donthamsetti, P. C., Broichhagen, J., Vyklicky, V., Stanley, C., Fu, Z., Visel, M., . . Isacoff, E. Y. (2019). Genetically Targeted Optical Control of an Endogenous G Protein-Coupled Receptor. J Am Chem Soc, 141(29), 11522-11530. doi: 10.1021/jacs.9b02895

Donthamsetti, P. C., Winter, N., Schonberger, M., Levitz, J., Stanley, C., Javitch, J. A., . . . Trauner, D. (2017). Optical Control of Dopamine Receptors Using a Photoswitchable Tethered Inverse Agonist. J Am Chem Soc, 139(51), 18522-18535. doi: 10.1021/jacs.7b07659

Farrants, H., Gutzeit, V. A., Acosta-Ruiz, A., Trauner, D., Johnsson, K., Levitz, J., \& Broichhagen, J. (2018). SNAPTagged Nanobodies Enable Reversible Optical Control of a G Protein-Coupled Receptor via a Remotely Tethered Photoswitchable Ligand. ACS Chem Biol, 13(9), 2682-2688. doi: 10.1021/acschembio.8b00628

Font, J., Lopez-Cano, M., Notartomaso, S., Scarselli, P., Di Pietro, P., Bresolí-Obach, R., . . Ciruela, F. (2017). Optical control of pain in vivo with a photoactive mGlu5 receptor negative allosteric modulator. Elife, 6. doi: $10.7554 /$ eLife. 23545

Gomez-Santacana, X., de Munnik, S. M., Vijayachandran, P., Da Costa Pereira, D., \& Bebelman, J. P. M., de Esch I. J. P., ... Leurs, R. (2018). Photoswitching the Efficacy of a Small-Molecule Ligand for a Peptidergic GPCR: from Antagonism to Agonism. Angew Chem Int Ed Engl, 57(36), 11608-11612. doi: 10.1002/anie.201804875

Gomez-Santacana, X., Pittolo, S., Rovira, X., Lopez, M., Zussy, C., Dalton, J. A., . . Llebaria, A. (2017). Illuminating Phenylazopyridines To Photoswitch Metabotropic Glutamate Receptors: From the Flask to the Animals. ACS Cent Sci, 3(1), 81-91. doi: 10.1021/acscentsci.6b00353

Gonzalez-Maeso, J., Ang, R. L., Yuen, T., Chan, P., Weisstaub, N. V., Lopez-Gimenez, J. F., . . Sealfon, S. C. (2008). Identification of a serotonin/glutamate receptor complex implicated in psychosis. Nature, 452(7183), 93-97. doi: 10.1038/nature06612

Gregory, K. J., \& Conn, P. J. (2015). Molecular Insights into Metabotropic Glutamate Receptor Allosteric Modulation. Mol Pharmacol, 88(1), 188-202. doi: 10.1124/mol.114.097220

Habermacher, C., Martz, A., Calimet, N., Lemoine, D., Peverini, L., Specht, A., . . . Grutter, T. (2016). Photoswitchable tweezers illuminate pore-opening motions of an ATP-gated P2X ion channel. Elife, 5, e11050. doi: 10.7554/eLife.11050

Hauwert, N. J., Mocking, T. A. M., Da Costa Pereira, D., Kooistra, A. J., Wijnen, L. M., Vreeker, G. C. M., ... Leurs, R. (2018). Synthesis and Characterization of a Bidirectional Photoswitchable Antagonist Toolbox for Real-Time GPCR Photopharmacology. J Am Chem Soc, 140(12), 4232-4243. doi: 10.1021/jacs.7b11422

Hauwert, N. J., Mocking, T. A. M., Da Costa Pereira, D., Lion, K., Huppelschoten, Y., Vischer, H. F., . . Leurs, R. (2019). A Photoswitchable Agonist for the Histamine H3 Receptor, a Prototypic Family A G-Protein-Coupled Receptor. Angew Chem Int Ed Engl, 58(14), 4531-4535. doi: 10.1002/anie.201813110

Hermanson, G. T. (2013). Chapter 1 - Introduction to Bioconjugation. In G. T. Hermanson (Ed.), Bioconjugate Techniques (Third Edition) (pp. 1-125). Boston: Academic Press.

Hull, K., Morstein, J., \& Trauner, D. (2018). In Vivo Photopharmacology. Chem Rev, 118(21), 10710-10747. doi: 10.1021/acs.chemrev.8b00037

Jeong, J. W., McCall, J. G., Shin, G., Zhang, Y., Al-Hasani, R., Kim, M., . . Rogers, J. A. (2015). Wireless Optofluidic Systems for Programmable In Vivo Pharmacology and Optogenetics. Cell, 162(3), 662-674. doi: 10.1016/j.cell.2015.06.058

Jones, B. J., Scopelliti, R., Tomas, A., Bloom, S. R., Hodson, D. J., \& Broichhagen, J. (2017). Potent Prearranged Positive Allosteric Modulators of the Glucagon-like Peptide-1 Receptor. Chemistry Open, 6(4), 501-505. doi: 10.1002/open.201700062

Kammermeier, P. J. (2012). Functional and pharmacological characteristics of metabotropic glutamate receptors 2/4 heterodimers. Mol Pharmacol, 82(3), 438-447. doi: 10.1124/mol.112.078501 
Kaplan, J. H., Forbush, B., 3rd, \& Hoffman, J. F. (1978). Rapid photolytic release of adenosine 5'-triphosphate from a protected analogue: utilization by the Na:K pump of human red blood cell ghosts. Biochemistry, 17(10), 1929-1935. doi: 10.1021/bi00603a020

Kenakin, T. (2005). New Concepts in Drug Discovery: Collateral Efficacy and Permissive Antagonism. Nature Reviews Drug Discovery, 4(11), 919-927. doi: 10.1038/nrd1875

Kenakin, T., \& Miller, L. J. (2010). Seven transmembrane receptors as shapeshifting proteins: the impact of allosteric modulation and functional selectivity on new drug discovery. Pharmacol Rev, 62(2), 265-304. doi: 10.1124/pr.108.000992

Kim, T. I., McCall, J. G., Jung, Y. H., Huang, X., Siuda, E. R., Li, Y., . . Bruchas, M. R. (2013). Injectable, cellularscale optoelectronics with applications for wireless optogenetics. Science, 340(6129), 211-216. doi: 10.1126/science.1232437

Klippenstein, V., Ghisi, V., Wietstruk, M., \& Plested, A. J. (2014). Photoinactivation of glutamate receptors by genetically encoded unnatural amino acids. J Neurosci, 34(3), 980-991. doi: 10.1523/jneurosci.372513.2014

Leach, K., Loiacono, R. E., Felder, C. C., McKinzie, D. L., Mogg, A., Shaw, D. B., . . Christopoulos, A. (2010). Molecular mechanisms of action and in vivo validation of an M4 muscarinic acetylcholine receptor allosteric modulator with potential antipsychotic properties. Neuropsychopharmacology, 35(4), 855-869. doi: 10.1038/npp.2009.194

Leach, K., Wen, A., Cook, A. E., Sexton, P. M., Conigrave, A. D., \& Christopoulos, A. (2013). Impact of clinically relevant mutations on the pharmacoregulation and signaling bias of the calcium-sensing receptor by positive and negative allosteric modulators. Endocrinology, 154(3), 1105-1116. doi: 10.1210/en.20121887

Leippe, P., Koehler Leman, J., \& Trauner, D. (2017). Specificity and Speed: Tethered Photopharmacology. ACS

Cent SCI, 56(39), 5214-5220. doi: 10.1021/acs.biochem.7b00687

Levitz, J., Pantoja, C., Gaub, B., Janovjak, H., Reiner, A., Hoagland, A., . . Isacoff, E. Y. (2013). Optical control of metabotropic glutamate receptors. Nat Neurosci, 16(4), 507-516. doi: 10.1038/nn.3346

Lindsley, C. W. (2014). 2013 Philip S. Portoghese Medicinal Chemistry Lectureship: drug discovery targeting allosteric sites. J Med Chem, 57(18), 7485-7498. doi: 10.1021/jm5011786

Liu, D., Xie, Y., Shao, H., \& Jiang, X. (2009). Using azobenzene-embedded self-assembled monolayers to photochemically control cell adhesion reversibly. Angew Chem Int Ed Engl, 48(24), 4406-4408. doi: 10.1002/anie. 200901130

Lopez-Cano, M., Font, J., Llebaria, A., Fernandez-Duenas, V., \& Ciruela, F. (2019). Optical Modulation of Metabotropic Glutamate Receptor Type 5 In Vivo Using a Photoactive Drug. Methods Mol Biol, 1947, 351359. doi: 10.1007/978-1-4939-9121-1_20

Maroteaux, L., Bechade, C., \& Roumier, A. (2019). Dimers of serotonin receptors: Impact on ligand affinity and signaling. Biochimie, 161, 23-33. doi: 10.1016/j.biochi.2019.01.009

McGirt, L. Y., Vasagar, K., Gober, L. M., Saini, S. S., \& Beck, L. A. (2006). Successful treatment of recalcitrant chronic idiopathic urticaria with sulfasalazine. Arch Dermatol, 142(10), 1337-1342. doi: 10.1001/archderm.142.10.1337

Mehta, Z. B., Johnston, N. R., Nguyen-Tu, M. S., Broichhagen, J., Schultz, P., Larner, D. P., . . Hodson, D. J. (2017). Remote control of glucose homeostasis in vivo using photopharmacology. Sci Rep, 7(1), 291. doi: 10.1038/s41598-017-00397-0

Morstein, J., Hill, R. Z., Novak, A. J. E., Feng, S., Norman, D. D., Donthamsetti, P. C., . . . Trauner, D. (2019). Optical control of sphingosine-1-phosphate formation and function. Nat Chem Biol, 15(6), 623-631. doi: 10.1038/s41589-019-0269-7

Noren, C. J., Anthony-Cahill, S. J., Griffith, M. C., \& Schultz, P. G. (1989). A general method for site-specific incorporation of unnatural amino acids into proteins. Science, 244(4901), 182-188. doi: 10.1126/science. 2649980

Pittolo, S., Gomez-Santacana, X., Eckelt, K., Rovira, X., Dalton, J., Goudet, C., . . . Gorostiza, P. (2014). An allosteric modulator to control endogenous G protein-coupled receptors with light. Nat Chem Biol, 10(10), 813-815. doi: 10.1038/nchembio.1612

Qazi, R., Gomez, A. M., Castro, D. C., Zou, Z., Sim, J. Y., Xiong, Y., . . Jeong, J. W. (2019). Wireless optofluidic brain probes for chronic neuropharmacology and photostimulation. Nat Biomed Eng, 3(8), 655-669. doi: 10.1038/s41551-019-0432-1

Rajagopal, S., Ahn, S., Rominger, D. H., Gowen-MacDonald, W., Lam, C. M., Dewire, S. M., . . Lefkowitz, R. J. (2011). Quantifying ligand bias at seven-transmembrane receptors. Mol Pharmacol, 80(3), 367-377. doi: 10.1124/mol.111.072801 
Rastogi, S. K., Zhao, Z., Barrett, S. L., Shelton, S. D., Zafferani, M., Anderson, H. E., . . Brittain, W. J. (2018). Photoresponsive azo-combretastatin A-4 analogues. Eur $\mathrm{J}$ Med Chem, 143, 1-7. doi: 10.1016/j.ejmech.2017.11.012

Reiner, A., \& Levitz, J. (2018). Glutamatergic Signaling in the Central Nervous System: Ionotropic and Metabotropic Receptors in Concert. Neuron, 98(6), 1080-1098. doi: 10.1016/j.neuron.2018.05.018Renner, C., \& Moroder, L. (2006). Azobenzene as conformational switch in model peptides. Chembiochem, 7(6), 868-878. doi: 10.1002/cbic. 200500531

Ricart-Ortega, M., Font, J., \& Llebaria, A. (2019). GPCR photopharmacology. Mol Cell Endocrinol, 488, 36-51. doi: 10.1016/j.mce.2019.03.003

Rovira, X., Trapero, A., Pittolo, S., Zussy, C., Faucherre, A., Jopling, C., . . . Llebaria, A. (2016). OptoGluNAM4.1, a Photoswitchable Allosteric Antagonist for Real-Time Control of mGlu4 Receptor Activity. Cell Chem Biol, 23(8), 929-934. doi: 10.1016/j.chembiol.2016.06.013

Samanta, S., Beharry, A. A., Sadovski, O., McCormick, T. M., Babalhavaeji, A., Tropepe, V., \& Woolley, G. A. (2013). Photoswitching azo compounds in vivo with red light. J Am Chem Soc, 135(26), 9777-9784. doi: 10.1021/ja402220t

Schonberger, M., \& Trauner, D. (2014). A photochromic agonist for mu-opioid receptors. Angew Chem Int Ed Engl, 53(12), 3264-3267. doi: 10.1002/anie.201309633

Shin, G., Gomez, A. M., Al-Hasani, R., Jeong, Y. R., Kim, J., Xie, Z., . . Rogers, J. A. (2017). Flexible Near-Field Wireless Optoelectronics as Subdermal Implants for Broad Applications in Optogenetics. Neuron, 93(3), 509-521.e503. doi: 10.1016/j.neuron.2016.12.031

Siewertsen, R., Neumann, H., Buchheim-Stehn, B., Herges, R., Nather, C., Renth, F., \& Temps, F. (2009). Highly efficient reversible Z-E photoisomerization of a bridged azobenzene with visible light through resolved $\mathrm{S}(1)(\mathrm{n}$ pi*) absorption bands. J Am Chem Soc, 131(43), 15594-15595. doi: 10.1021/ja906547d

Siewertsen, R., Schonborn, J. B., Hartke, B., Renth, F., \& Temps, F. (2011). Superior Z-->E and E-->Z photoswitching dynamics of dihydrodibenzodiazocine, a bridged azobenzene, by S1(npi`) excitation at lambda = 387 and $490 \mathrm{~nm}$. Phys Chem Chem Phys, 13(3), 1054-1063. doi: 10.1039/c0cp01148g

Suratman, S., Leach, K., Sexton, P., Felder, C., Loiacono, R., \& Christopoulos, A. (2011). Impact of species variability and 'probe-dependence' on the detection and in vivo validation of allosteric modulation at the M4 muscarinic acetylcholine receptor. $\mathrm{Br} \mathrm{J}$ Pharmacol, 162(7), 1659-1670. doi: 10.1111/j.14765381.2010.01184.x

Szymanski, W., Wu, B., Poloni, C., Janssen, D. B., \& Feringa, B. L. (2013). Azobenzene photoswitches for Staudinger-Bertozzi ligation. Angew Chem Int Ed Engl, 52(7), 2068-2072. doi: 10.1002/anie.201208596

Taura, J., Nolen, E. G., Cabre, G., Hernando, J., Squarcialupi, L., Lopez-Cano, M., . . Ciruela, F. (2018). Remote control of movement disorders using a photoactive adenosine A2A receptor antagonist. $J$ Control Release, 283, 135-142. doi: 10.1016/j.jconrel.2018.05.033

Thapaliya, E. R., Zhao, J., \& Ellis-Davies, G. C. R. ACS Chem Neurosci. doi: 10.1021/acschemneuro.8b00734

Tochitsky, I., Trautman, J., Gallerani, N., Malis, J. G., \& Kramer, R. H. (2017). Restoring visual function to the blind retina with a potent, safe and long-lasting photoswitch. Sci Rep, 7, 45487. doi: 10.1038/srep45487

Trads, J., Hull, K., Matsuura, B. S., Laprell, L., Fehrentz, T., Gorldt, N., . . Trauner, D. (2019). Sign Inversion in Photopharmacology: Incorporation of Cyclic Azobenzenes in Photoswitchable Potassium Channel Blockers and Openers. Angew Chem Int Ed Engl. doi: 10.1002/anie.201905790

Tsai, Y. H., Essig, S., James, J. R., Lang, K., \& Chin, J. W. (2015). Selective, rapid and optically switchable regulation of protein function in live mammalian cells. Nat Chem, 7(7), 554-561. doi: 10.1038/nchem.2253

Velema, W. A., Szymanski, W., \& Feringa, B. L. (2014). Photopharmacology: beyond proof of principle. J Am Chem Soc, 136(6), 2178-2191. doi: 10.1021/ja413063e

Wagner, N., Schuhmacher, M., Lohmann, A., \& Nadler, A. (2019). A Coumarin Triflate Reagent Enables One-Step Synthesis of Photo-Caged Lipid Metabolites for Studying Cell Signaling. Chemistry - A European Journal, n/a(n/a). doi: 10.1002/chem.201903909

Warther, D., Gug, S., Specht, A., Bolze, F., Nicoud, J. F., Mourot, A., \& Goeldner, M. (2010). Two-photon uncaging: New prospects in neuroscience and cellular biology. Bioorg Med Chem, 18(22), 7753-7758. doi: 10.1016/j.bmc.2010.04.084

Watson, C., Jenkinson, S., Kazmierski, W., \& Kenakin, T. (2005). The CCR5 receptor-based mechanism of action of 873140, a potent allosteric noncompetitive HIV entry inhibitor. Mol Pharmacol, 67(4), 1268-1282. doi: 10.1124/mol.104.008565

Westphal, M. V., Schafroth, M. A., Sarott, R. C., Imhof, M. A., Bold, C. P., Leippe, P., . . Frank, J. A. (2017). Synthesis of Photoswitchable Delta(9)-Tetrahydrocannabinol Derivatives Enables Optical Control of Cannabinoid Receptor 1 Signaling. J Am Chem Soc, 139(50), 18206-18212. doi: 10.1021/jacs.7b06456 
Wood, M. R., Hopkins, C. R., Brogan, J. T., Conn, P. J., \& Lindsley, C. W. (2011). "Molecular switches" on mGluR allosteric ligands that modulate modes of pharmacology. Biochemistry, 50(13), 2403-2410. doi: 10.1021/bi200129s

Wootten, D., Christopoulos, A., Marti-Solano, M., Babu, M. M., \& Sexton, P. M. (2018). Mechanisms of signalling and biased agonism in G protein-coupled receptors. Nat Rev Mol Cell Biol, 19(10), 638-653. doi: 10.1038/s41580-018-0049-3

Yin, S., Noetzel, M. J., Johnson, K. A., Zamorano, R., Jalan-Sakrikar, N., Gregory, K. J., . . . Niswender, C. M. (2014). Selective actions of novel allosteric modulators reveal functional heteromers of metabotropic glutamate receptors in the CNS. J Neurosci, 34(1), 79-94. doi: 10.1523/jneurosci.1129-13.2014

Zbaida, S. (1995). The mechanism of microsomal azoreduction: predictions based on electronic aspects of structure-activity relationships. Drug Metab Rev, 27(3), 497-516. doi: 10.3109/03602539508998333

Zussy, C., Gomez-Santacana, X., Rovira, X., De Bundel, D., Ferrazzo, S., Bosch, D., . . . Goudet, C. (2018). Dynamic modulation of inflammatory pain-related affective and sensory symptoms by optical control of amygdala metabotropic glutamate receptor 4. Mol Psychiatry, 23(3), 509-520. doi: 10.1038/mp.2016.223

\section{Figure 1}

A. Schematic representation of the photo-uncaging approach. The photoactive caged-compound is inactive under dark light conditions, but when exposed to a select wavelength of light the active molecule is irreversibly released and allowed to interact with its target receptor. B. Structure and photochemistry of the photo-caged compound, JF-NP-026 (caged- raseglurant). Upon irradiation with $405 \mathrm{~nm}$ of light the mGlu5 NAM, raseglurant, is irreversibly released.

\section{Figure 2}

Schematic representations of the different classes of tethered photoswitchable ligands available for targeting GPCRs. A. Photoswitchable tethered ligands (PTLs) B. photoswitchable orthogonal remotely tethered ligands (PORTLs), C. Nanotweezer, D. membrane anchored photoswitchable orthogonal remotely tethered ligands (maPORTL).

\section{Figure 3}

A. Schematic representation of the photoisomerization of a photochromic ligand (PCL). Following irradiation with a select wavelength of light, photoisomerization of a PCL is promoted, and the PCL can then return back to the more stable isomer via thermal relaxation or irradiation with a second wavelength B. Structure and photochemistry of the photoswitchable, mGlu5 NAM, alloswitch-1, which interconverts from trans to cis isomeric forms following irradiation with UV light, and from cis to trans upon exposure to green light or via thermal relaxation. 


\section{Figure 4}

Photoswitchable cores that can interconvert between trans and cis or closed and open forms. A. azobenzenes, B. stilbenes, C. hemi-thioindigos, D. fulgides, E. spiropyrans, F. diarylethenes.

\section{Figure 5}

The photoinduced potency shift (pPPS) measures the change in potency of a photoswitchable ligand following irradiation with a single wavelength of light as compared to its potency under dark light conditions. The above schematic represents the interaction of a photoswitchable NAM with an $80 \%$ effective concentration (EC80) of agonist under different light conditions to provide an estimate of the pPPS for the interaction.

\section{Figure 6}

A. The signalling of a target receptor can be modulated in a graded manner by changing the light intensity and wavelength used to photoisomerize a PCL. B. Different wavelengths of light can also result in distinctly different pharmacological effects such that many different conditions can be tested in the one assay in real-time and in a reversible manner. 
A

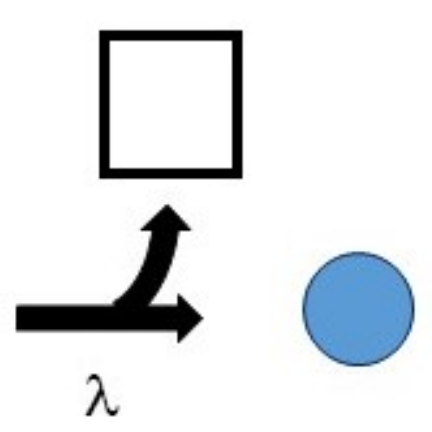

B

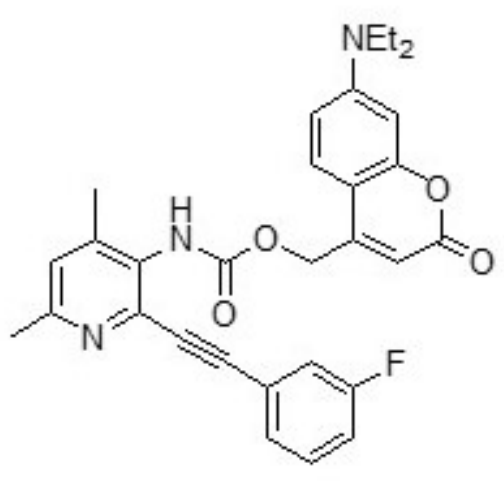

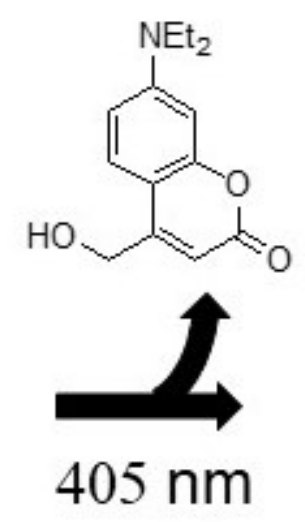

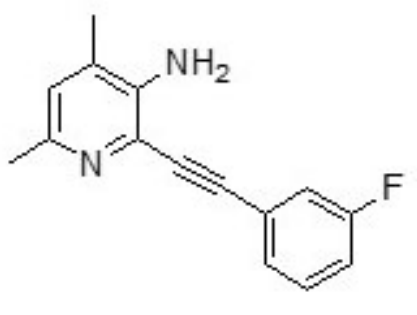


A 
A

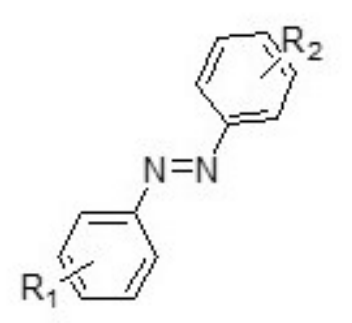

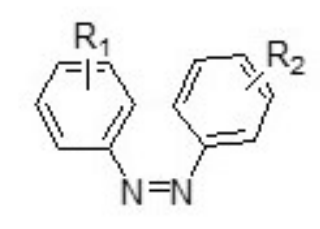

$\lambda 2$ or $\mathrm{K}_{\mathrm{B}} \mathrm{T}$

B
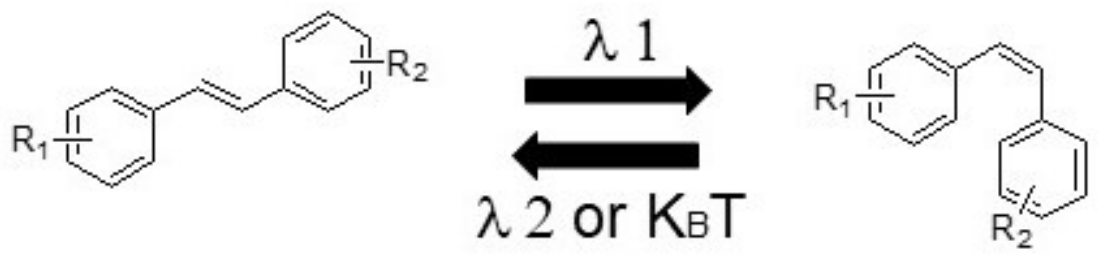

C

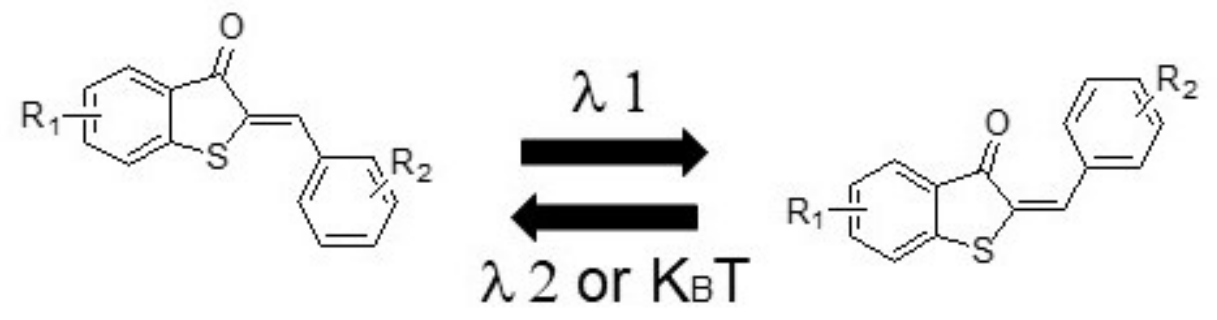

D
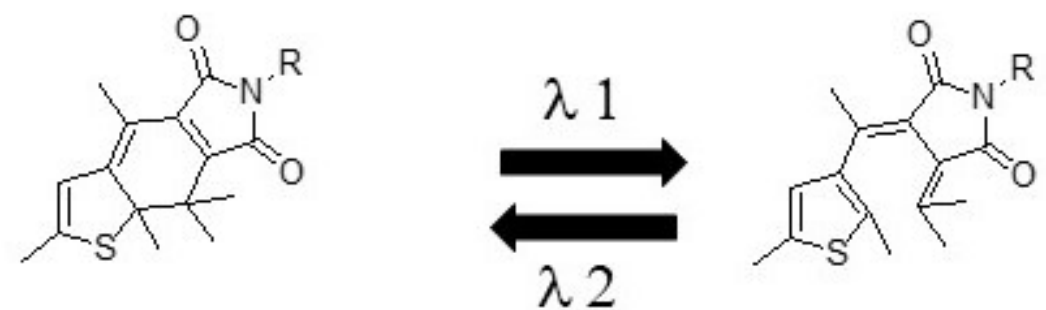

E

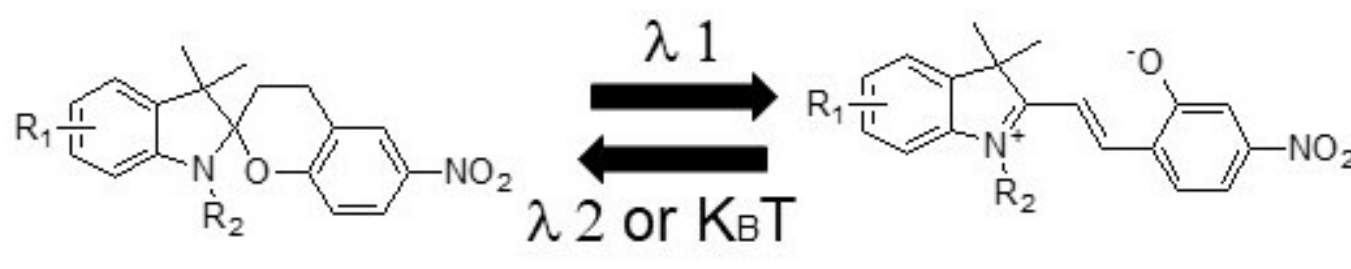

F
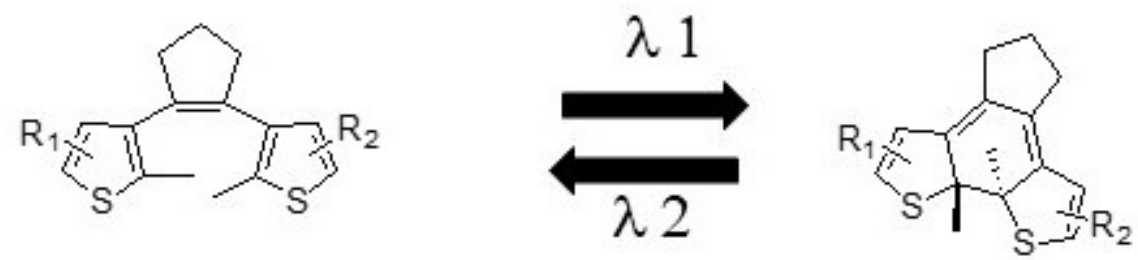


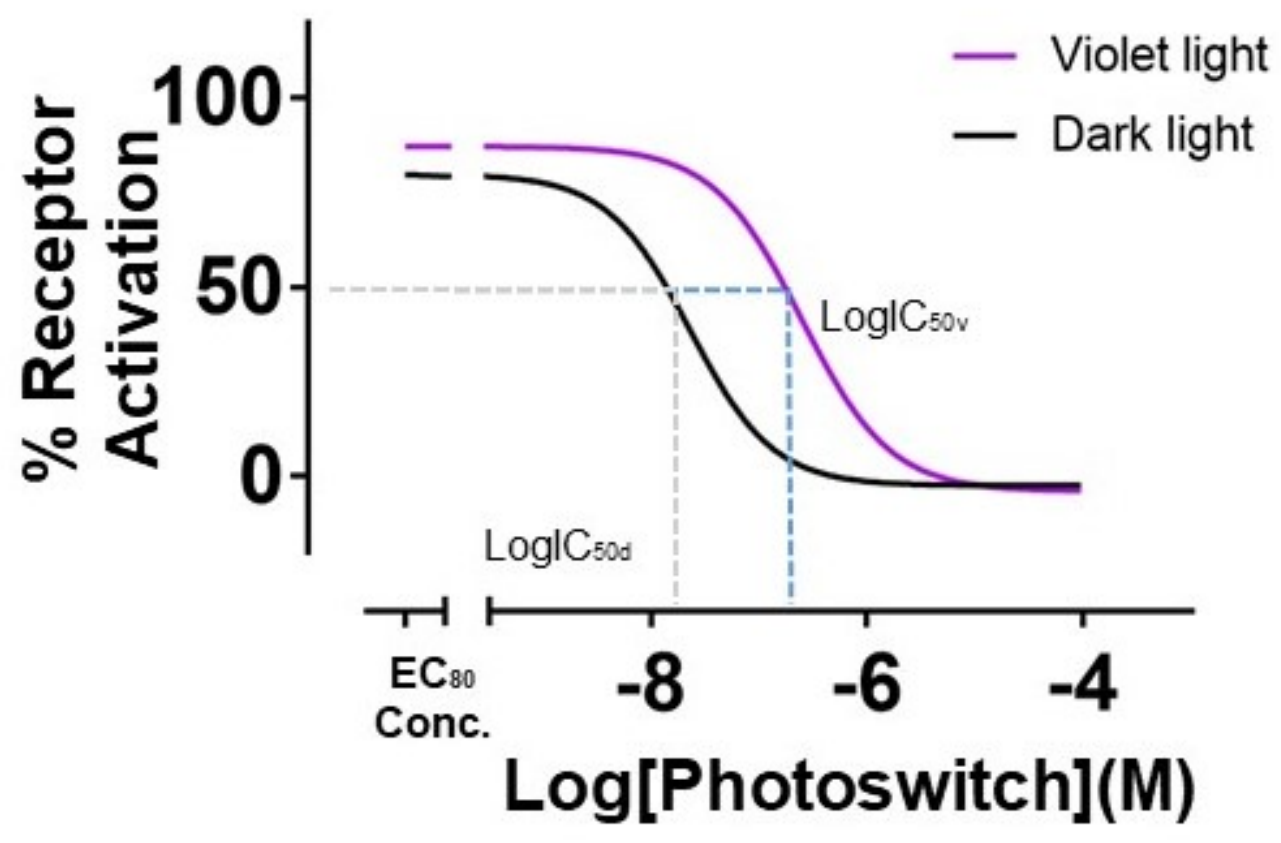



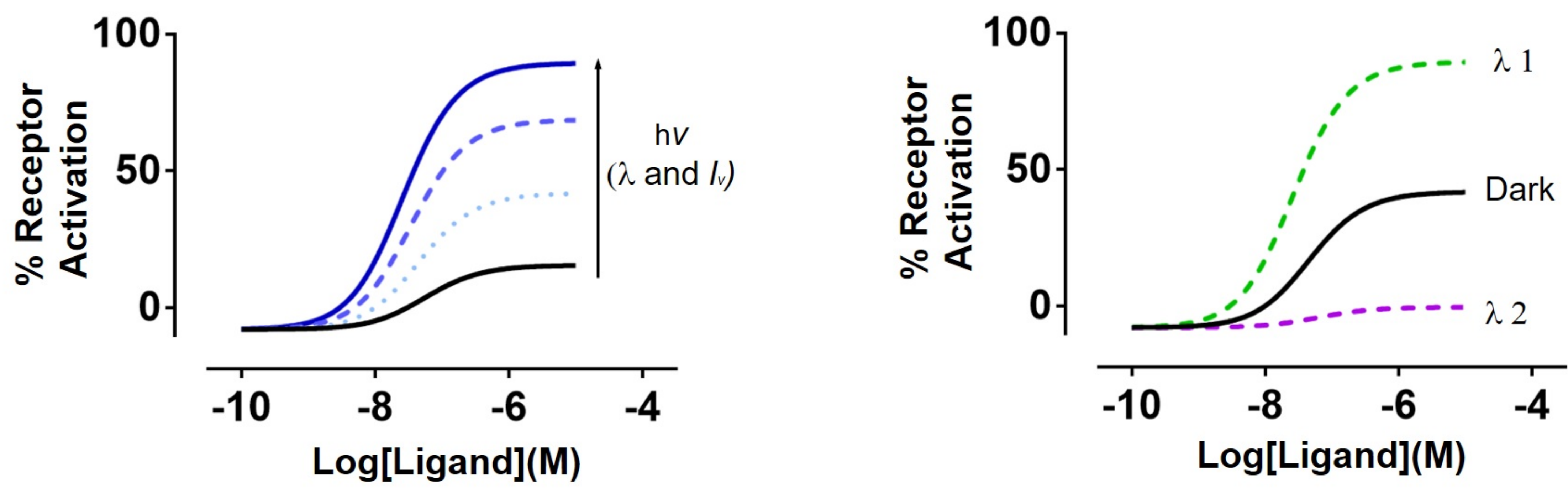